\title{
Article \\ Effects of Pressure and Coal Rank on the Oxy-Fuel Combustion of Pulverized Coal
}

\author{
Dingyi Qin, Qianyun Chen ${ }^{(0)}$, Jing Li * and Zhaohui Liu (])
}

Citation: Qin, D.; Chen, Q.; Li, J.; Liu, Z. Effects of Pressure and Coal Rank on the Oxy-Fuel Combustion of Pulverized Coal. Energies 2022, 15, 265. https://doi.org/10.3390/ en15010265

Academic Editor: Osvalda Senneca

Received: 22 November 2021

Accepted: 28 December 2021

Published: 31 December 2021

Publisher's Note: MDPI stays neutral with regard to jurisdictional claims in published maps and institutional affiliations.

Copyright: (C) 2021 by the authors. Licensee MDPI, Basel, Switzerland. This article is an open access article distributed under the terms and conditions of the Creative Commons Attribution (CC BY) license (https:// creativecommons.org/licenses/by/ $4.0 /)$.
State Key Laboratory of Coal Combustion, School of Energy and Power Engineering, Huazhong University of Science and Technology, Wuhan 430074, China; qindy@hust.edu.cn (D.Q.); win@hust.edu.cn (Q.C.); zliu@hust.edu.cn (Z.L.)

* Correspondence: jingli@hust.edu.cn; Tel.: +86-27-8755-2151

\begin{abstract}
Pressurized oxy-fuel combustion technology is the second generation of oxy-fuel combustion technology and has low energy consumption and low cost. In this research, a visual pressurized flat-flame reaction system was designed. A particle-tracking image pyrometer (PTIP) system based on a high-speed camera and an SLR camera was proposed. Combining the experimental system and data-processing method developed, the ignition and combustion characteristics of a single coal particle between 69 and $133 \mu \mathrm{m}$ in size were investigated. The results indicated that at atmospheric pressure, the ignition delay time of ShanXi (SX) anthracite coal was longer than that of ShenHua (SH) bituminous coal, while that of PRB sub-bituminous coal was the shortest. As the pressure rose, the ignition delay time of the PRB sub-bituminous coal and SX anthracite coal showed a continuous increasing trend, while the ignition delay time of SH bituminous coal showed a trend of first increasing and then decreasing. Moreover, pressure also affects the pyrolysis process of coal. As the pressure increases, it became more difficult to release the volatiles produced by coal pyrolysis, which reduced the release rate of volatiles during the ignition stage, and prolonged the release time and burning duration time of volatiles.
\end{abstract}

Keywords: pressurized oxy-fuel combustion; single coal particle; ignition characteristics; flat-flame burner optical diagnosis

\section{Introduction}

According to the 2020 China Statistical Annual [1], coal combustion still occupies a crucial position in China's energy generation system, and coal combustion is the main source of greenhouse gas emissions around the world. How to achieve the efficient and low-carbon use of coal is an important problem that needs to be solved urgently. Oxyfuel combustion technology uses high-purity oxygen instead of combustion air based on the existing power plant boilers and flue gas circulation technology to obtain highconcentration carbon dioxide flue gas, which can condense and compress enriched carbon dioxide for permanent storage. Due to its ease of implementation and ability to achieve a better economic efficiency, this currently seems to be the most promising combustion technology for reducing $\mathrm{CO}_{2}$ emissions effectively. At the beginning of the 21st century, the American company ThermoEnergy first proposed the specific concept of a pressurized oxy-fuel power generation system [2,3]. Zheng et al. [4,5] stated that the pressurization process can effectively reduce energy loss, improve combustion heat efficiency, and cut down $\mathrm{CO}_{2}$ emissions.

The improvement of the combustion efficiency and stability of industrial burners could be achieved through the further study of the mechanism of pulverized coal combustion and the creation of models. However, the volatile burning stage of pulverized coal reflects the radiation characteristics of the pulverized coal flame, which has a greater impact on the entire combustion process. It takes only a short time for pulverized coal to enter the burner with the airflow until it burns out-about $10 \mathrm{~s}$. The ignition characteristics will directly 
affect the flame stability, the ignition height, and the generation and emission of pollutants. Being influenced by many factors simultaneously, the background atmosphere, oxygen concentration, particle size, coal rank, heating rate, and ambient temperature of pulverized coal combustion will not only affect the ignition and combustion process but also change their mode [6-8]. Many researchers have measured the radiation characteristics [9-16], morphological dimensions, and other aspects of the ignition process of pulverized coal under atmospheric pressure and studied the influence of factors such as ambient temperature, oxygen concentration, and background atmosphere on its ignition and combustion. However, suitable experimental systems under the right pressure conditions have a complex structure and high cost, while the existing pressurized experimental benches are relatively scarce and there are relatively few research results. Zhi et al. [17] used a thermogravimetric analyzer to study the ignition of pulverized coal under different pressures and oxygen concentrations and found that an increase in pressure promoted the pyrolysis and combustion of pulverized coal and caused the pulverized coal to ignite in advance. Zheng et al. [18] believed that increasing the pressure would change the ignition mode of pulverized coal and correspondingly reduce the ignition delay time, which can improve the net efficiency and reduce the cost. Lin. et al. [19] studied the ignition of $6 \mathrm{~mm}$ briquettes using a pressurized visualized fluidized bed and found that with the increase in environmental pressure, the ignition delay time increased, the size of the volatile flame became larger, and the burnout time became shorter. Therefore, the influence of pressure on the pulverized coal combustion process is complex. The ignition and combustion characteristics of pulverized coal depend largely on the experimental bench used. The flat-flame combustion device is a new method that has become more and more popular in recent years. Lewis and Ma et al. [20,21] first constructed a pressurized flat-flame reaction device using an atmospheric flat-flame burner. This was based on the use of sampling and analysis to study the gasification process of pulverized coal. However, the heating rate of pulverized coal in existing experimental benches, such as in pressurized thermogravimetry, pressurized heat network reactors, and pressurized dropper furnaces, is low (the highest is no more than $10^{4} \mathrm{k} / \mathrm{s}$, which is one or two orders of magnitude lower than the heating rate of pulverized coal in an actual furnace (about $\left.10^{5}-10^{6} \mathrm{k} / \mathrm{s}\right)$ ). Moreover, the high heating rate of existing pressurized carrier flow reactors based on flat-flame burners means that they all have a short optical diagnostic window; thus, it is not possible to obtain the combustion characteristics of pulverized coal under pressure with these, including the ignition delay, ignition duration time, and particle temperature.

In addition, traditional contact measurements and sampling methods are of limited use in high-temperature and high-pressure experimental environments. To measure the change in the combustion characteristic parameters in the process of pulverized coal combustion in real time, a non-contact optical diagnostic measurement method has been adopted. Shaddix et al. [6] used an ICCD camera with a filter for two-color pyrometry and measured the velocity of coal particles. Schiemann et al. [22] used two-color pyrometry to measure temperature and collect images of burning particles from two directions, effectively locating the position of particles and analyzing their shape. Köser et al. [23] arranged a laser trigger device, a bidirectional backlight high-speed camera, and a laser-induced fluorescence device in a furnace to analyze the ignition time of the volatile gas of a single coal particle.

At present, existing studies lack detailed pressure ignition combustion data concerning discrete pulverized coal under extreme environments (high pressure, high temperature, high heating rate), and the study of single particles under pressurized conditions has also led to higher requirements for measurement methods. Most methods focus on obtaining the particle size, shape, and surface temperature of char, but it is difficult to capture the characteristics of the volatile combustion stage. Therefore, research on the ignition and combustion characteristics of pulverized coal under pressurized oxy-fuel conditions is essential for the development of pressurized oxy-fuel combustion technology, which can be used to develop ignition combustion models and volatile burning models under pressurized conditions. Additionally, research on the ignition and combustion of single 
particles will reveal the mechanism behind the ignition and combustion of pulverized coal, which is of great value in both theory and engineering applications.

\section{Experimental Methods}

\subsection{Experimental Setup}

To study the ignition and combustion characteristics of pulverized coal under pressurized oxy-fuel conditions, in this experiment we used a flat-flame burner designed by Chen Qianyun et al. [24]. The schematics of the reactor are shown in Figure 1. The ambient gas temperature of the burner furnace could be controlled between 1200 and $2000 \mathrm{~K}$, and the heating rate used was $10^{5}-10^{6} \mathrm{~K} / \mathrm{s}$. The designed pressure range was $1-30 \mathrm{bar}$, while the working pressure range was 1-15 bar. The maximum residence time of particles in the furnace was 200-600 ms, and it could provide $\mathrm{O}_{2} / \mathrm{N}_{2}$ and $\mathrm{O}_{2} / \mathrm{CO}_{2}$ atmospheres with different oxygen concentration ranges.

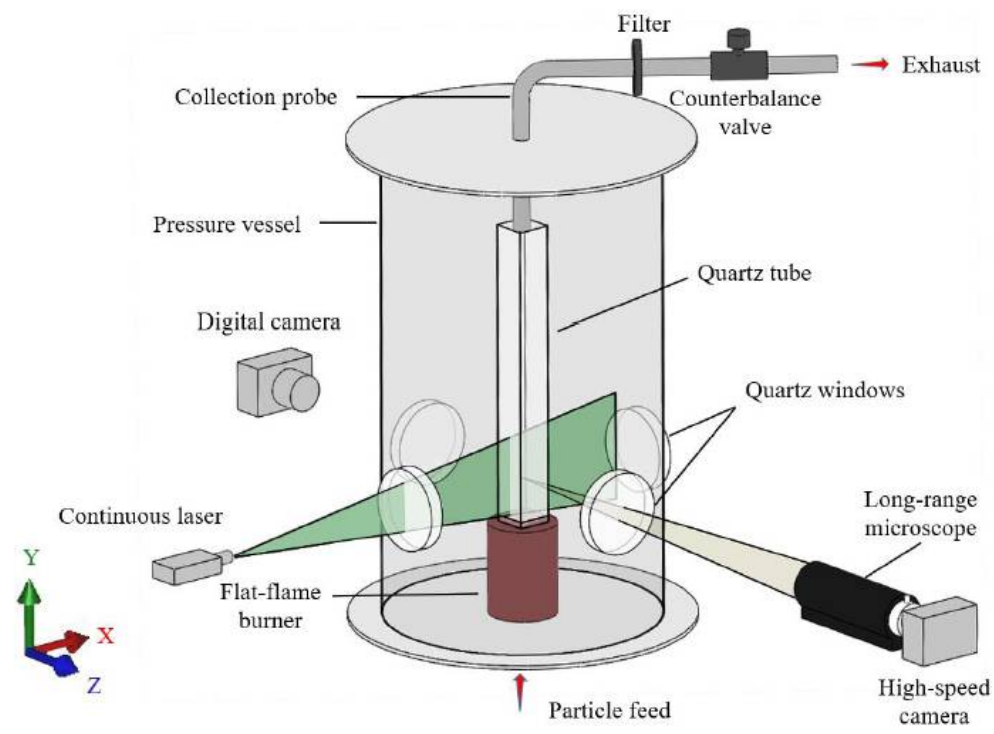

Figure 1. Schematics of the reactor.

The particle-tracking image pyrometer (PTIP) system proposed in this work was composed of a high-resolution high-speed camera (FASTCAM Mini AX200), a digital SLR camera (Nikon D70), and a $532 \mathrm{~nm}$ continuous laser, as shown in Figure 2. Based on the continuous particle images taken by high-speed cameras and the existing pulverized coal identification and tracking methods [24], it was possible to identify and track the effectively burned particles.

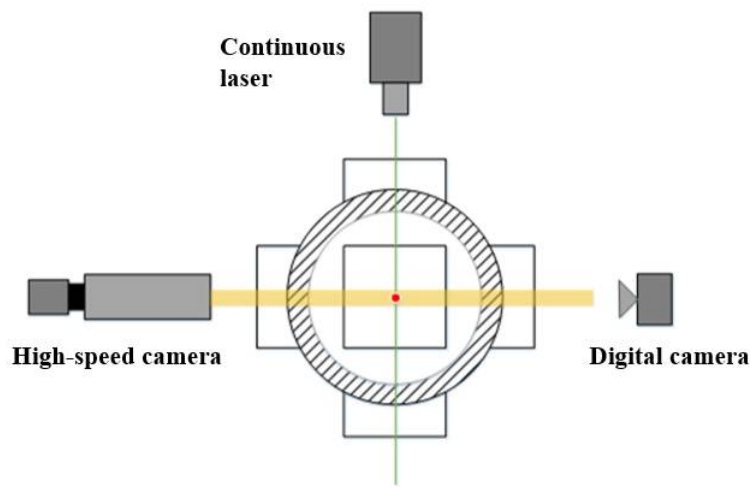

Figure 2. Schematics of the PTIP system. 


\subsection{Methods of Data Processing}

\subsubsection{Identification of Devolatilizing Particles}

According to the radiation characteristics of the particles, a volatile particle identification method, which was based on a cross-correlation identification method for grayscale images, was established [25]. This method establishes a template of typical volatile particles, calculates the cross-correlation of the original grayscale particle images, and finally recognizes the volatile particles based on a threshold. Once the template is determined, the cross-correlation coefficient of each particle can be obtained through:

$$
C(k)=\frac{\sum_{X_{i}=-M / 2}^{M / 2} \sum_{Y_{i}=-N / 2}^{N / 2}\left(I\left(X_{i}, Y_{i}\right)-I_{a v g}\right)\left(G\left(X_{i}, Y_{i}\right)-G_{a v g}\right)}{\left(\sum_{X_{i}=-M / 2}^{M / 2} \sum_{Y_{i}=-N / 2}^{N / 2}\left(I\left(X_{i}, Y_{i}\right)-I_{a v g}\right)^{2}\right)^{1 / 2}\left(\sum_{X_{i}=-M / 2}^{M / 2} \sum_{Y_{i}=-N / 2}^{N / 2}\left(G\left(X_{i}, Y_{i}\right)-G_{a v g}\right)^{2}\right)^{1 / 2}}
$$

where $C(k)$ is the cross-correlation coefficient of the particle labeled $k ; M$ and $N$ are the horizontal and vertical lengths of the images in pixels, respectively; $G\left(X_{i}, Y_{i}\right)$ and $G T\left(X_{i}, Y_{i}\right)$ represent the gray values of the pixel points $\left(X_{i}, Y_{i}\right)$ in the particle image and the template image, respectively; $G_{a v g}$ and $G T_{a v g}$ are the average gray values of all pixels accordingly.

The heating stage, devolatilization stage, and oxidation stage of char can be clearly distinguished by adding laser assistance in the firing process of the actual experiment. The continuous images of pulverized coal particles are shown in Figures 3 and 4 . The number of shooting frames was 6400 FPS and the size of the extracted particle image was $151 \times 151$ pixels.

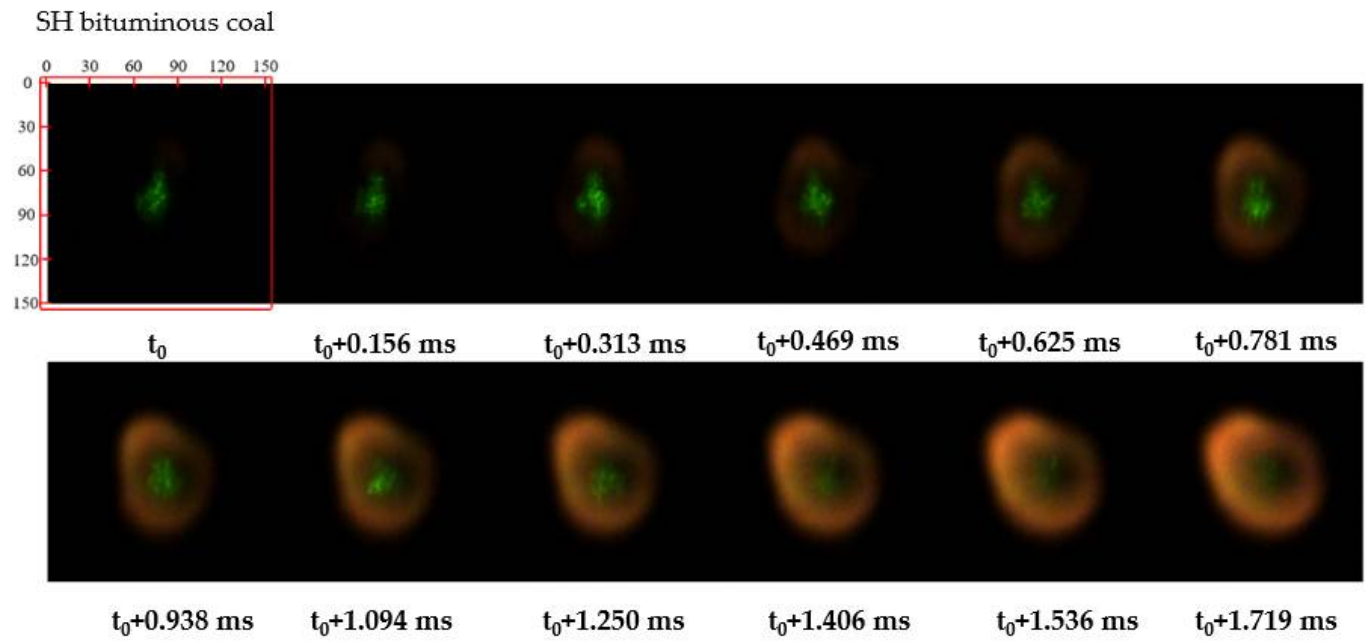

Figure 3. Continuous images of pulverized coal particles from the heating stage to the volatile burning stage.

When the particles were in the preheating stage, the temperature was low and the external radiation was weak. No spontaneous light was detected, and the particles were mainly green. When the particles entered the volatile burning stage, the volatiles released were ignited and an irregular volatile flame was formed around the particle. After removing the laser, a dark inner hole appeared; the final stage was heterogeneous char combustion. Compared with the volatile burning stage, the particle size at this stage was relatively small, but they were bright at the beginning and darkened gradually until the end of the process. Moreover, the results were consistent with those observed by other researchers [26]. 
SH bituminous coal

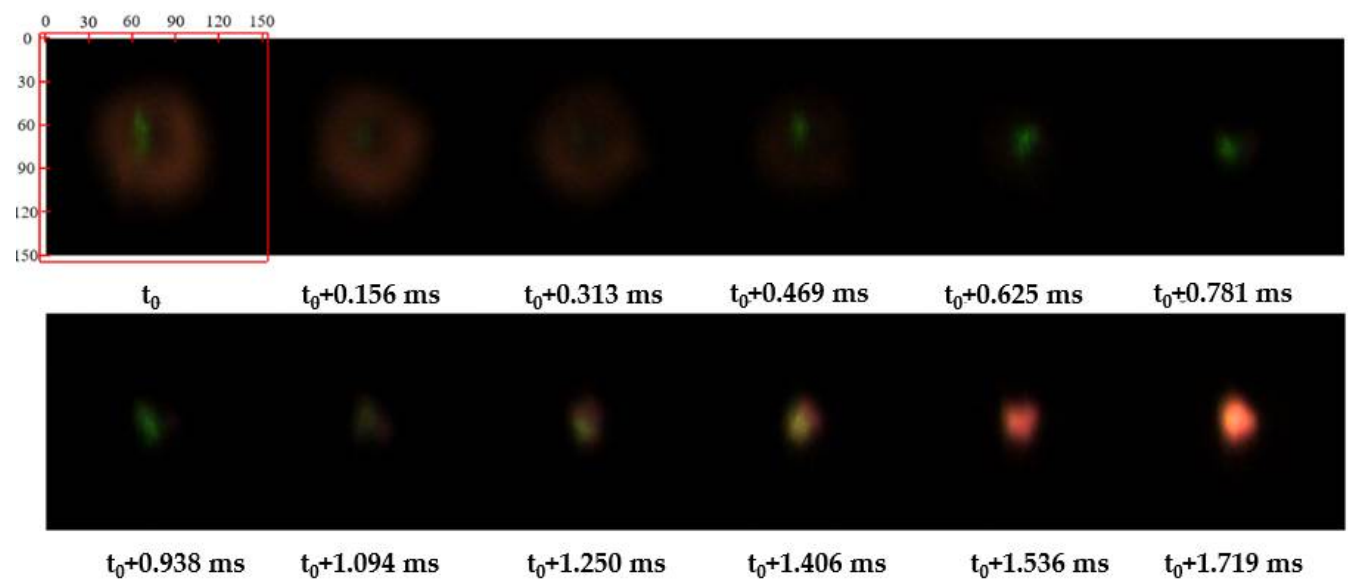

Figure 4. Continuous images of pulverized coal particles from the volatile burning stage to the char combustion stage.

\subsubsection{Determination of Ignition Delay Time}

Using the digital SLR camera with a $135 \mathrm{~mm}$ lens to take long-exposure shots of pulverized coal flames, the flame trajectory of the particles injected into the furnace to the middle of the particle combustion stage could be obtained in the same picture and the starting position of the fire could be judged from a macro perspective. To make the long-exposure trajectory of the particles clearer and more obvious, an image preprocessing method was used, as shown in Figure 5a,b, to remove the scattered light of the quartz tube and the plane flame luminescence. Meanwhile, the anomalous scattered particle tracks were eliminated through region identification. Referring to the study of Yinhe Liu et al. [12], in this paper we converted the particle trajectory picture into a grayscale picture, calculated the overall grayscale value of the flame track along the height direction, and plotted the grayscale distribution curve along the height direction (as shown in Figure 5c). It was found that when the particles ignited, the brightness of the particles increased significantly. After the volatile burning phase was over, the particles entered the char combustion stage and the brightness was also affected by the char combustion particles, showing a distribution trend of a sharp increase at first and then a slow decline. A total of $50 \%$ of the maximum gray value was selected as the ignition point to represent the ignition position of half of the particles in a statistical sense. The ignition height could be determined from the long-exposure pictures, while the ignition delay time could be calculated according to the particle velocity.

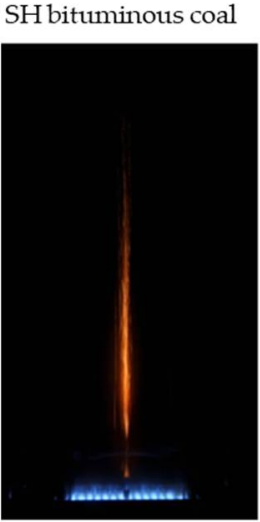

(a)

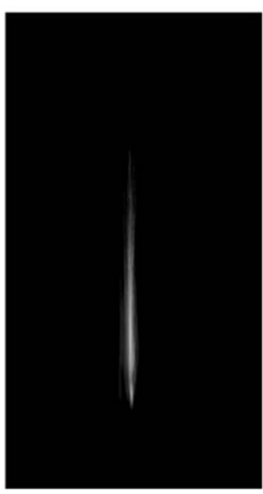

(b)

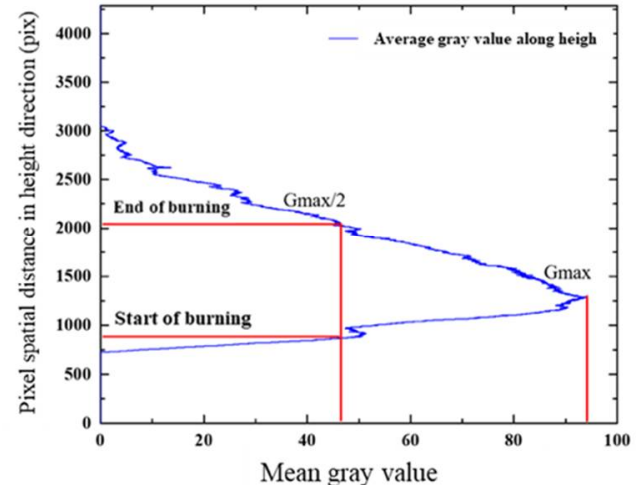

(c)

Figure 5. (a) The long-exposure original picture; (b) the grayscale picture after long-exposure processing; (c) the grayscale distribution curve along the height direction. 
Based on the continuous images taken by the high-speed camera, the ignition delay time could also be analyzed from a microscopic perspective and compared with the judgment method for long-exposure pictures. For homogeneous ignition with a high amount of volatile coal, the ignition delay time could be obtained by using normal distribution cumulative function fitting and selecting $10 \%$ of the frequency distribution to remove abnormal particles at the ignition starting point. Figure 6 shows the $90 \%$ position as the end of the volatile burning stage.

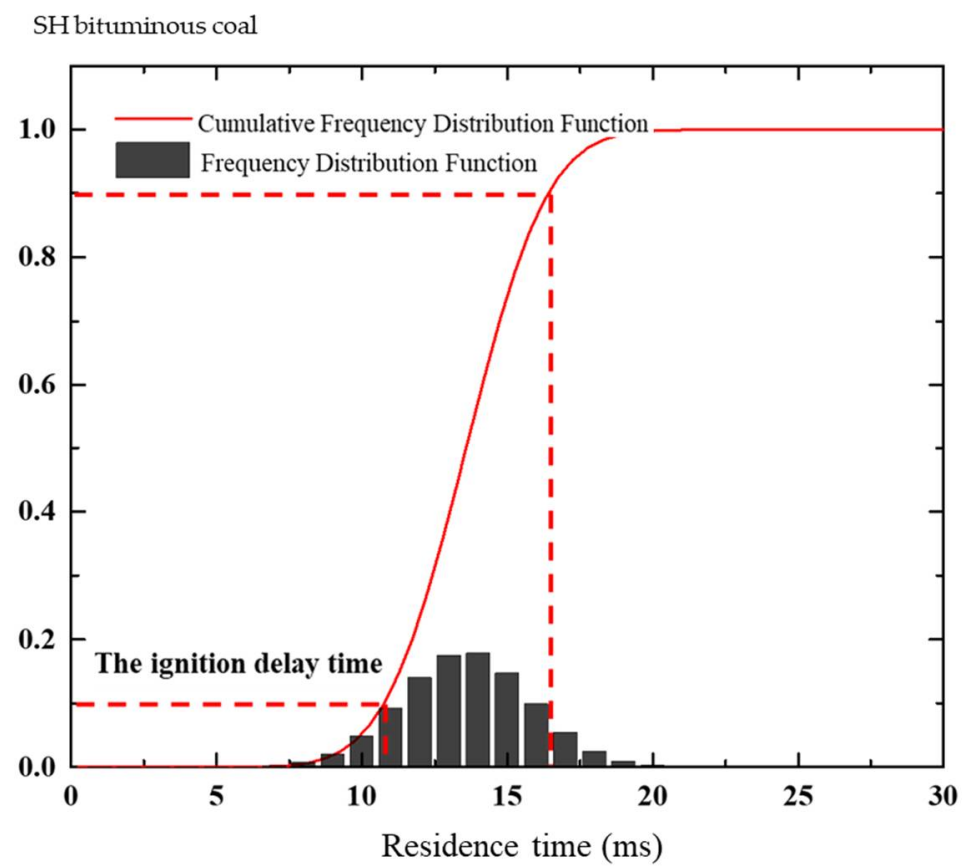

Figure 6. Method of micro frequency distribution.

The data of SH bituminous coal under oxy-fuel conditions at 1, 3, 5, 7, and 10 bar were selected for judgment, respectively; the results are shown in Figure 7. It was found that the determination result of the macroscopic statistical angle of the long-exposure picture was consistent with the determination result of the statistical frequency distribution of the microscopic particles. In terms of actual values, the result of the long-exposure image judgment method was similar to that of the particle frequency judgment method when the threshold value was 50\%. The purpose of this was to cause the obtained data to be less affected by the fluctuation of powder supply and by a few abnormal ignited particles.

\subsubsection{Two-Color Pyrometry}

Based on the continuous images of effective particles captured by color high-speed cameras, the particle temperature was calculated using image pyrometry. Due to the characteristics of the photosensitive unit and filter, the accuracy of the high-speed camera was slightly lower than that of traditional methods, but it could obtain instantaneous two-dimensional radiation information and calculate the spatial distribution of the temperature [24].

\subsection{Fuels and Experimental Conditions}

In this work, the ignition and combustion of Shenhua bituminous coal, PRB subbituminous coal, and Shanxi anthracite coal under $20 \% \mathrm{O}_{2} / \mathrm{CO}_{2}$ conditions were investigated. The experimental conditions and gas compositions of the flue gas are listed in Table 1. The core temperature of the reactor was $1400 \mathrm{~K}$ after the correction of the temperature measurement, and the particle heating rate was as high as $10^{5}-10^{6} \mathrm{~K} / \mathrm{s}$. A small particle feeding rate of $0.3 \mathrm{~g} / \mathrm{h}$ was chosen to enable the spacing between particles to be no less than 20 times the particle diameter. 
SH bituminous coal

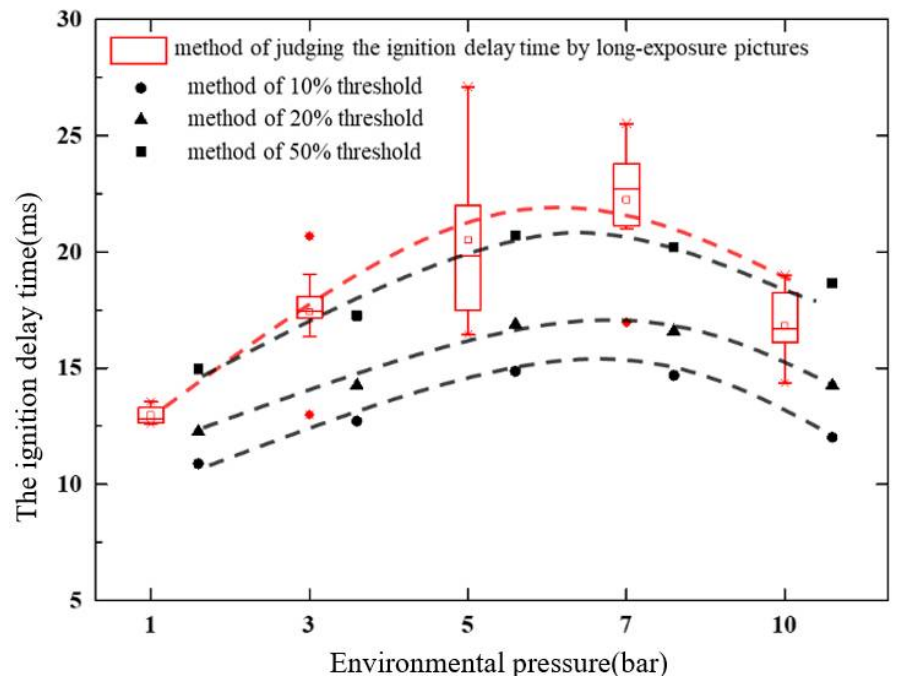

Figure 7. Comparison of the method used for judging the ignition delay time by long-exposure pictures and micro-particle statistics.

Table 1. Experimental conditions and gas compositions of the flue gas.

\begin{tabular}{|c|c|c|c|c|c|}
\hline \multirow{2}{*}{ Coal } & \multirow{2}{*}{$\frac{\text { Pressure }}{\text { atm }}$} & \multirow{2}{*}{$\frac{\text { Gas Temperature }}{\mathrm{K}}$} & \multicolumn{3}{|c|}{ Gas Composition } \\
\hline & & & $\mathrm{O}_{2}$ & $\mathrm{CO}_{2}$ & $\mathrm{H}_{2} \mathrm{O}$ \\
\hline \multirow{3}{*}{ PRB sub-bituminous } & 1 & 1400 & $20 \%$ & $78.22 \%$ & $1.78 \%$ \\
\hline & 5 & 1400 & $20 \%$ & $79.65 \%$ & $0.35 \%$ \\
\hline & 10 & 1400 & $20 \%$ & $79.65 \%$ & $0.35 \%$ \\
\hline \multirow{5}{*}{ Shenhua bituminous } & 1 & 1400 & $20 \%$ & $78.22 \%$ & $1.78 \%$ \\
\hline & 3 & 1400 & $20 \%$ & $79.43 \%$ & $0.57 \%$ \\
\hline & 5 & 1400 & $20 \%$ & $79.65 \%$ & $0.35 \%$ \\
\hline & 7 & 1400 & $20 \%$ & $79.66 \%$ & $0.34 \%$ \\
\hline & 10 & 1400 & $20 \%$ & $79.65 \%$ & $0.35 \%$ \\
\hline \multirow{3}{*}{ Shanxi anthracite } & 1 & 1400 & $20 \%$ & $78.22 \%$ & $1.78 \%$ \\
\hline & 5 & 1400 & $20 \%$ & $79.65 \%$ & $0.35 \%$ \\
\hline & 10 & 1400 & $20 \%$ & $79.65 \%$ & $0.35 \%$ \\
\hline
\end{tabular}

The diameter of the three coal particles was in the range of $69-133 \mu \mathrm{m}$, and the proximate and ultimate analyses are listed in Table 2. Figure 8 shows the size distributions of three kinds of coal particles.

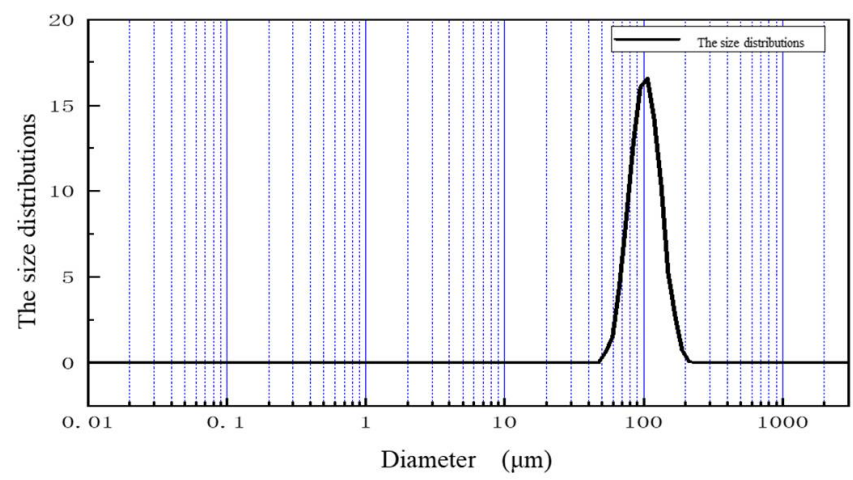

Figure 8. The size distributions of three kinds of coal particles. 
Table 2. Experimental conditions and gas compositions of the flue gas.

\begin{tabular}{cccc}
\hline Coal & PRB Sub-Bituminous & SH Bituminous & SX Anthracite \\
\hline & \multicolumn{1}{c}{ Elemental analysis (wt.\%, ad) } \\
\hline Water & 1.47 & 1.26 & 0.40 \\
Ash & 7.11 & 13.89 & 23.18 \\
Volatiles & 54.72 & 48.27 & 21.60 \\
Fixed carbon & 36.7 & 36.58 & 51.22 \\
\hline \multicolumn{5}{c}{ Elemental analysis (wt. \%, ad) } \\
H & 67.99 & 64.44 & 60.6 \\
$\mathrm{~N}$ & 4.45 & 3.76 & 3.27 \\
$\mathrm{~S}$ & 1.27 & 1.08 & 1.16 \\
$\mathrm{O}$ & 0.55 & 0.36 & 2.36 \\
\hline
\end{tabular}

\section{Results and Discussions}

\subsection{Micromorphology of Different Coals during Ignition and Combustion}

Currently, it is generally believed that there are three ignition modes for pulverized coal. The first is homogeneous ignition: ignition occurs in a gas-phase reaction. When the pulverized coal is heated to a certain temperature, it begins to pyrolyze and releases volatile components. The gaseous volatile components react with oxygen to cause ignition. The second type is heterogeneous ignition; the ignition occurs on the surface of coal particles and oxygen directly contacts their surfaces, causing a violent oxidation reaction and fire. Additionally, the third type of ignition is heterogeneous-homogeneous composite ignition: after heterogeneous ignition occurs on the surface of char, the homogeneous ignition of volatiles occurs immediately.

Through the microscopic dynamic capture of the experimental process in different types of coal, SH bituminous coal was found to have a higher volatile content. When the particles were sprayed into the furnace, the particles began to undergo a rapid pyrolysis reaction. Subsequently, the concentration of soot around the particles gradually increased, the uneven reaction on the surface of the particles was quickly blocked, the temperature gradually rose, the concentration of volatile gas increased, and a fire occurred. This turned into a homogeneous ignition process. Therefore, the ignition combustion mode of $\mathrm{SH}$ bituminous coal can be divided into three stages - a pre-heating process, a volatile burning process, and a coal char burning process-as shown in Figure 9a.

PRB sub-bituminous coal is a kind of sub-bituminous coal with a high volatile content, and its ignition and combustion processes are similar to those of Shenhua bituminous coal. The combustion process is also divided into three stages - a pre-heating process, a volatile burning process, and a coal char burning process-as shown in Figure 9b. However, due to the obvious directionality of some particles during the volatile combustion process, the volatile compounds are ejected rapidly in a certain direction, and some sub-bituminous coal particles will produce irregular volatile coating flames.

SX anthracite coal is a kind of anthracite with a low volatile content and a high fixed carbon content. Its ignition and combustion processes have typical ignition characteristics for anthracite, mainly being characterized by out-of-phase ignition. The actual combustion process is shown in Figure 9c. Compared with SH bituminous coal and PRB sub-bituminous coal, SX anthracite coal has a higher pyrolysis temperature, a lower volatilization rate, and an insufficient volatilization concentration. Therefore, the surface of pulverized coal is oxidized directly by contact with oxygen, and only a small amount of volatiles are oxidized inside or on the surface of particles. The combustion process can be divided into two stages: a pre-heating process and a coal char burning process, which is dominated by a heterogeneous oxidation reaction. 


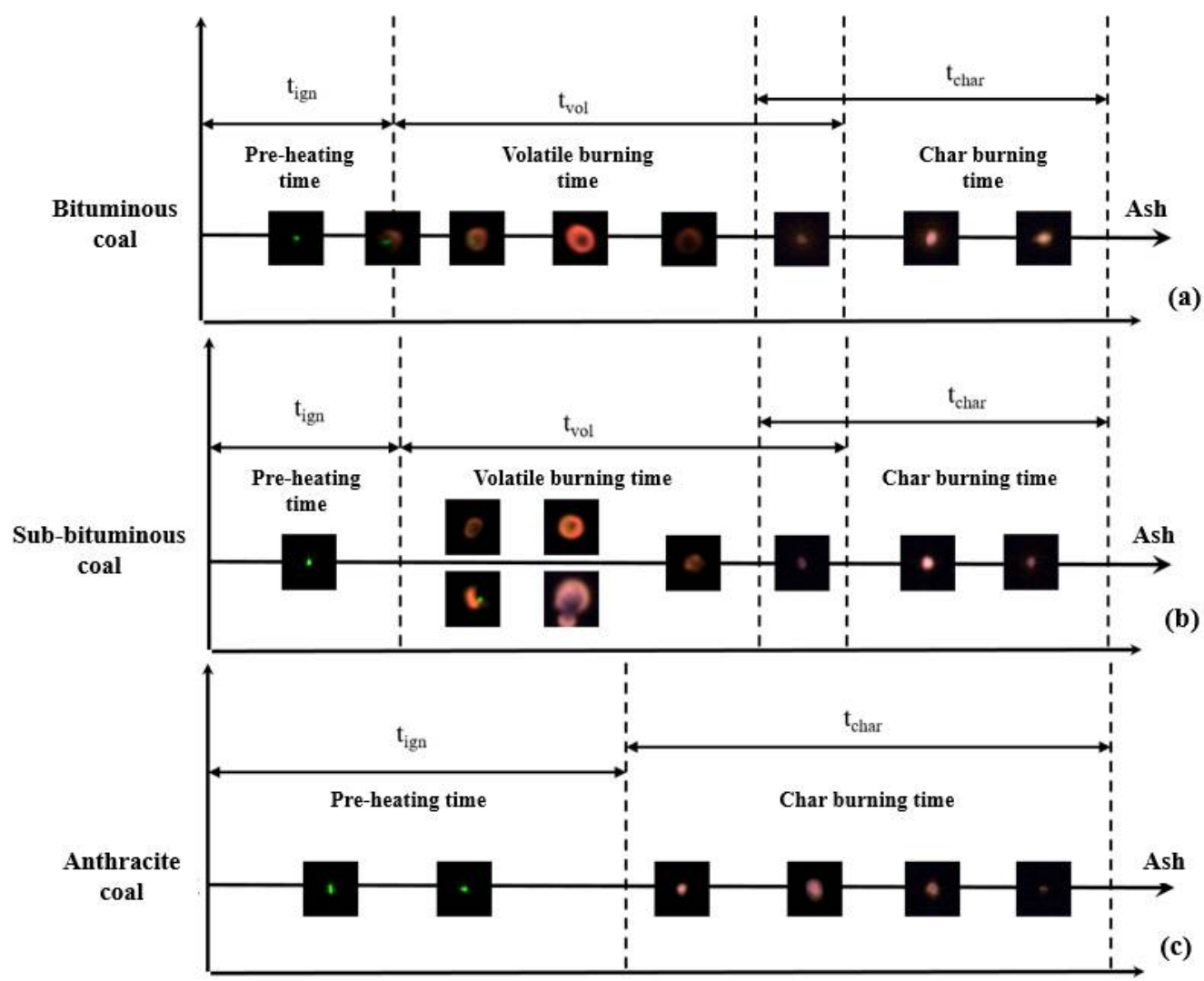

Figure 9. (a) The ignition process of $\mathrm{SH}$ bituminous coal; (b) the ignition process of PRB subbituminous coal; (c) the ignition process of SX anthracite coal.

\subsection{Effect of Pressure on the Ignition Delay Time}

Pressure has different effects on the ignition delay time of pulverized coal. From Figure 10a, it can be seen that a long exposure can capture the complete combustion process of PRB sub-bituminous coal and Shenhua bituminous coal, but not the burn-out process of Shanxi anthracite coal.

According to the methods detailed in Section 2.2.2, the particle velocity distribution curves of three types of coal powder under environments with different pressures were obtained, as shown in Figure 10b. Under the same pressure, the velocity curves of the three types of pulverized coal were in the same range. Combining the ignition points obtained from the long-exposure pictures with the velocity curves allowed us to obtain the box plots of the ignition delay time of the three types of pulverized coal, as shown in Figure 11.

From the results of the boxplot, it can be seen that under atmospheric pressure, the ignition delay time for homogeneous sub-bituminous coal and bituminous coal increased with the increase in the number of coal rank, while that of bituminous coal was longer than that of sub-bituminous coal. High-rank coals with a low volatile content had a high pyrolysis temperature and a low content of volatile compounds. Oxygen directly contacted the surface of the particles, causing a lower out-of-phase ignition. However, the low-rank coals with a high volatile content were less difficult to pyrolyze. Rapid pyrolysis produced a large number of irregular volatile flames that coated the surface of the particles. Oxygen and volatile gas ignited homogeneously and caught fire more quickly. 

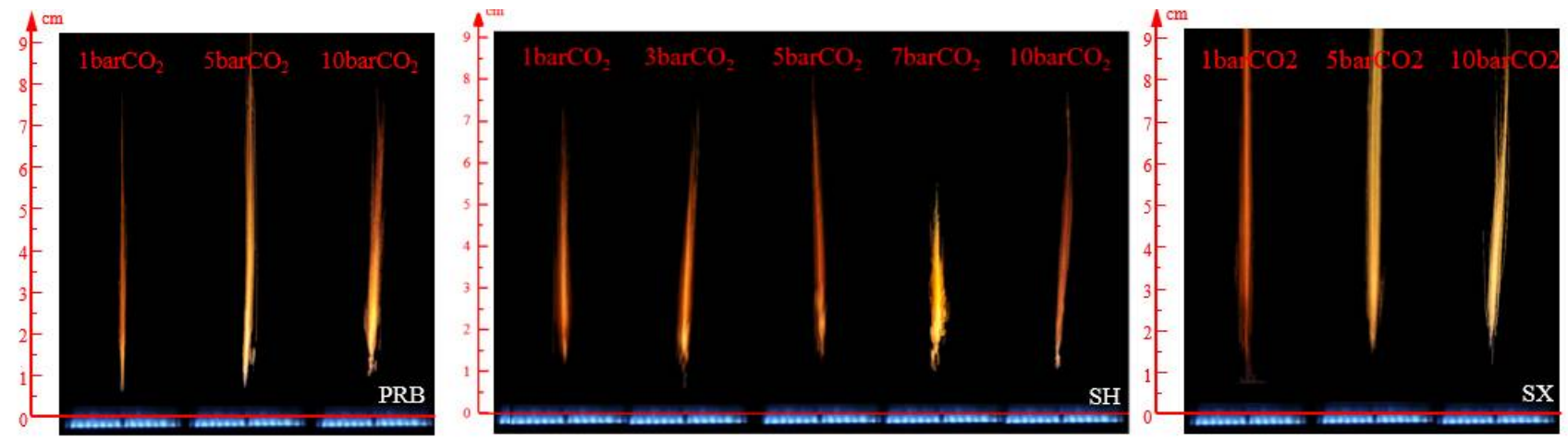

(a)

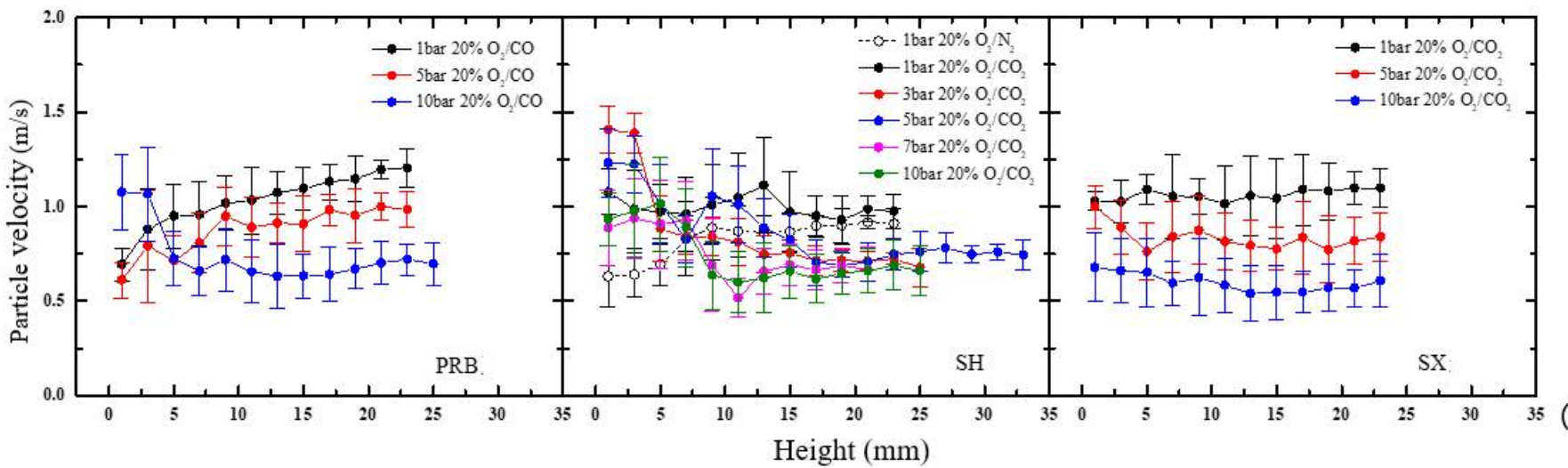

Figure 10. (a) Long-exposure images of three kinds of pulverized coal under different pressures; (b) particle velocity of three kinds of pulverized coal under different pressures.

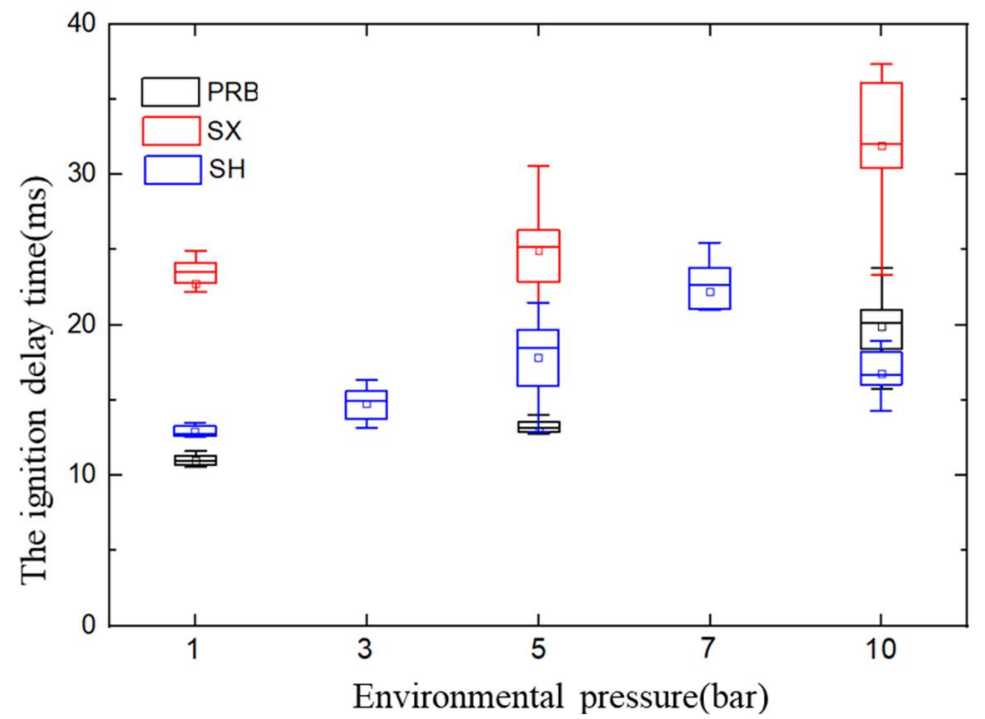

Figure 11. Box plot of the ignition delay time for three kinds of pulverized coal under different pressures.

The effect of pressure competition on the ignition delay time is more complicated. When the pressure was 1 bar, 5 bar, and 10 bar, the ignition delay time of PRB subbituminous coal and SX anthracite increased monotonically with the increase in pressure. However, the ignition delay time of SH bituminous coal at 1, 3, 5, 7, and 10 bar showed a trend of increasing first and then decreasing. When the ambient pressure began to increase, the particle heating rate decreased, the two factors of volatile analysis obstruction became dominant, and the ignition delay time increased. With the further increase in pressure, the increase in the oxygen partial pressure and the decrease in the pyrolysis temperature 
dominated the volatile ignition and the ignition delay time began to decrease. For PRB sub-bituminous coal, the volatile release rate during the pyrolysis stage was lower than that of Shenhua bituminous coal. The lower the coal rank was, the less the pyrolysis temperature decreased and the higher the concentration of the volatile around the particles was. If it was also relatively lower, the effect of increased oxygen partial pressure was weaker. Therefore, the inflection points of the ignition delay change in PRB sub-bituminous coal may be under higher environmental pressure, which could not be observed within the pressure range of this experiment. However, Shanxi anthracite coal is different from the other two coals because of its high rank and low volatile content. It is mainly characterized by out-of-phase ignition, which is greatly affected by a decrease in the heating rate. With the increase in the pressure, the out-of-phase ignition delay time increased monotonically.

Therefore, under the same pressure, the ignition delay time of the three ranks of coal at 1 bar and 5 bar decreased with the increase in coal rank. This is because the activation energy of the particle pyrolysis increased with the increase in the coal rank, making it harder to catch fire. However, at 10 bar the ignition delay time did not change continuously with the coal rank due to the influence of higher pressure. The ignition then occurred in the order of Shenhua bituminous coal, PRB sub-bituminous coal, and SX anthracite coal.

\subsection{Effect of Pressure on the Duration of Volatile Combustion}

By identifying the volatile characteristics of Shenhua bituminous coal and PRB subbituminous coal under various working conditions, all volatile flame particles were screened out and the temperature of the volatile flame particles was obtained statistically, as shown in Figure 12. The combustion temperature of the three ranks of pulverized coal at 1-10 bar was in the range of 1000-1800 K. With the increase in pressure, the average temperature of the three kinds of pulverized coal increased. This is because as the pressure increased, the partial pressure of oxygen also increased, thus accelerating the all-phase and heterogeneous oxidation reaction speed and raising the temperature of the three kinds of pulverized coal.
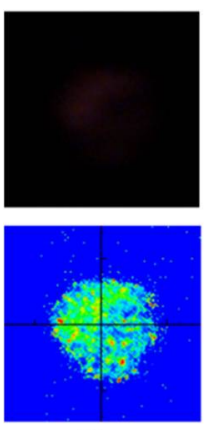

1 bar
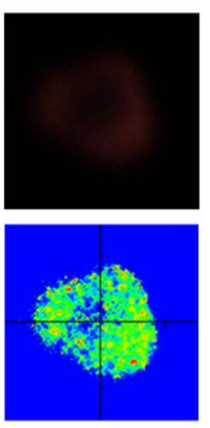

1bar
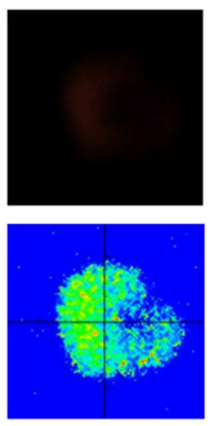

5bar
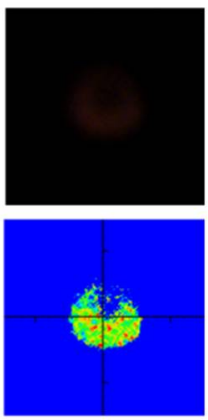

5 bar
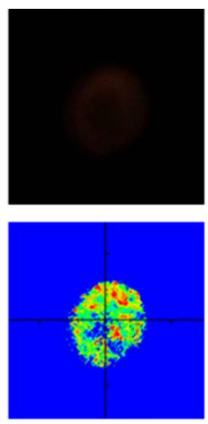

10bar

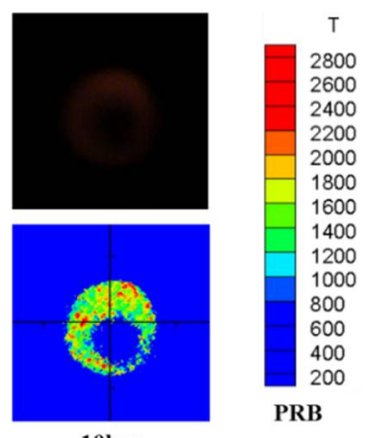

10bar

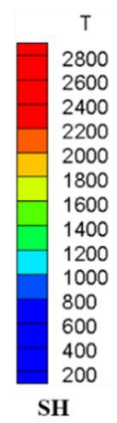

.
Figure 12. The transient temperature distribution of $\mathrm{SH}$ bituminous coal and PRB sub-bituminous coal volatile combustion under different pressures.

The average flame temperature of $\mathrm{SH}$ bituminous coal volatiles was higher than that of PRB sub-bituminous coal and higher than that of SX anthracite coal under a pressure 
of 1 bar to 5 bar. This was because under atmospheric pressure, bituminous coal and subbituminous coal mainly burned together with the volatiles, and due to the volatiles diffusing outwards the reaction was more uniform. Bituminous coal has a fast rate of precipitation of volatiles and a high concentration of volatiles. Compared with sub-bituminous coal, its reaction was more violent, meaning that the temperature was higher. On the other hand, SX anthracite coal generally underwent heterogeneous reactions, which are greatly affected by the oxygen diffusion effect, and its reaction temperature was relatively lower than that of the more highly volatile coals. With the further increase in pressure, both the homogeneous and heterogeneous reaction rates increased and sub-bituminous coal and bituminous coal were inhibited by the diffusion of volatile matter. The increase in the oxygen partial pressure of $S X$ anthracite coal made the oxygen supply more sufficient and caused the reaction degree to increase sharply. Currently, the combustion temperature of SX anthracite coal is higher than that of two kinds of coal with high volatile and low metamorphic contents.

The residence time-frequency distribution of volatile combustion particles captured by PRB sub-bituminous coal under various working conditions was analyzed statistically using the volatile image recognition method and the particle frequency ignition judgment method; the results were compared with those of $\mathrm{SH}$ bituminous coal. Figure 13a shows the distribution curve of particle cumulative frequency with the residence time, while Figure $13 \mathrm{~b}$ shows the time results of the volatile burning characteristics.

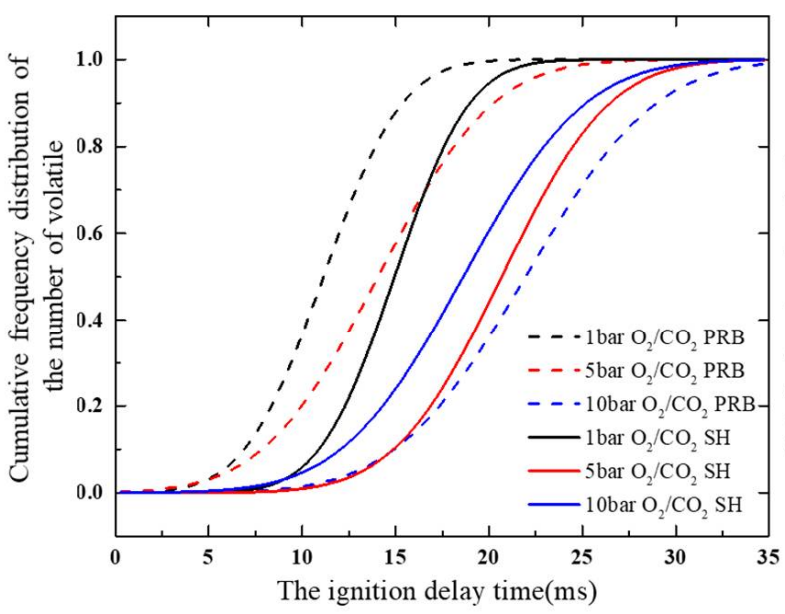

(a)

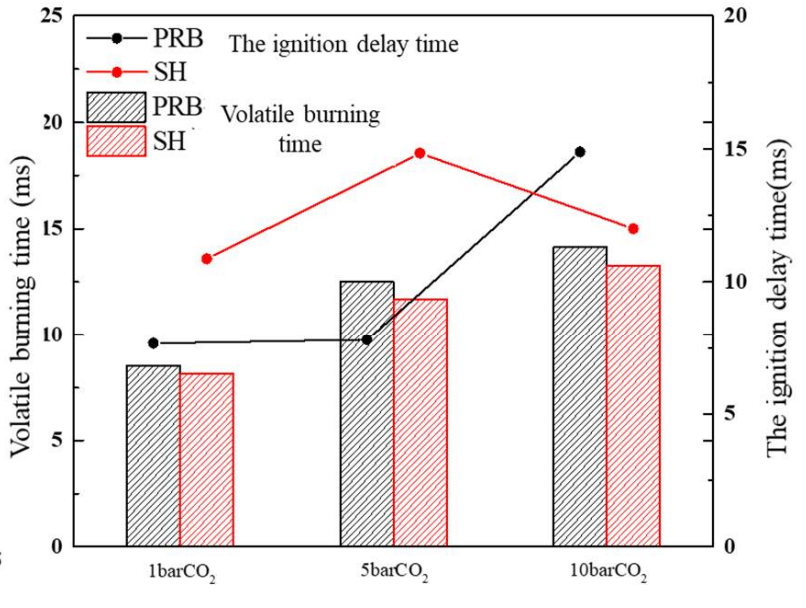

(b)

Figure 13. Burning time characteristics of Shenhua bituminous coal and PRB sub-bituminous coal under different working conditions: (a) cumulative frequency curve of volatile particle distribution; (b) volatile burning time.

The initial burning time of $\mathrm{SH}$ bituminous coal volatiles was consistent with the ignition delay time determined by the long-exposure pictures, showing a trend of first increasing and then decreasing. Additionally, the initial burning time range was 10-15 ms. Under oxy-fuel conditions, the combustion duration of volatile compounds increased gradually from $8.14 \mathrm{~ms}$ at 1 bar to $13.25 \mathrm{~ms}$ at $10 \mathrm{bar}$ with increasing pressure. As the pressure increases, it became more difficult to release the volatiles produced by coal pyrolysis, which reduced the release rate of volatiles during ignition stage, and prolonged the release and the duration time of the volatiles. The initial combustion time of the volatile compounds of PRB sub-bituminous coal increased, which conformed to the rule of long-term exposure. The combustion time of volatile matter also increased monotonically with the increase in pressure. Due to the high volatile content of PRB sub-bituminous coal, the volatile release time lasted longer. Therefore, the burning time of the volatile content of the PRB sub-bituminous coal was longer than that of the SH bituminous coal. 
However, the homogeneous oxidation reaction of SX anthracite coal and a small number of pyrolysis products occurred simultaneously. With the increase in pressure, the oxygen partial pressure of SX anthracite coal increased and its homogeneous and heterogeneous reaction rates increased. Meanwhile, those of sub-bituminous coal and bituminous coal were suppressed due to the diffusion of volatile matter, meaning that the ignition temperature of anthracite was higher.

\section{Conclusions}

In this paper, three typical pulverized coals-PRB sub-bituminous coal, $\mathrm{SH}$ bituminous coal, and SX anthracite coal-were selected for the research of the macroscopic ignition delay characteristics and the microscopic morphology characteristics of the combustion stage. The experiment was performed in an oxy-fuel atmosphere of 1-10 bar at a temperature of $1400 \mathrm{~K}$ and an oxygen concentration of $20 \%$. Our conclusions are as follows:

1. At atmospheric pressure, the ignition delay time of $S X$ anthracite coal was longer than that of SH bituminous coal, while the PRB sub-bituminous coal was the shortest. Under pressurized conditions, the ignition delay time of PRB sub-bituminous coal and SX anthracite coal increased with the increase in pressure. As the reduction in the pyrolysis temperature of bituminous coal was larger than that of sub-bituminous coal, the ignition delay time of bituminous coal was shorter than that of bituminous coal; moreover, the ignition delay time of SH bituminous coal firstly increased and then decreased;

2. Volatile compounds appear in the combustion process of homogeneous ignition coal. Pressure also affects the pyrolysis process of coal. As the pressure increases, it became more difficult to release the volatiles produced by coal pyrolysis, which reduced the release rate of volatiles during the ignition stage, and prolonged the release time and burning duration time of the volatiles. Since the volatile content of PRB subbituminous coal was higher than that of $\mathrm{SH}$ bituminous coal, the volatile analysis rate was lower and the process lasted longer. Therefore, the devolatilization duration time of volatiles in PRB sub-bituminous coal was longer.

Author Contributions: Conceptualization, D.Q. and Q.C.; methodology, D.Q. and Q.C.; formal analysis, D.Q.; data curation, Q.C.; writing-original draft preparation, D.Q.; supervision, J.L.; project administration, Z.L.; funding acquisition, Z.L. All authors have read and agreed to the published version of the manuscript.

Funding: This research was funded by the National Key Research and Development Program of China, grant number 2019YFE0100100.

Institutional Review Board Statement: Not applicable.

Informed Consent Statement: Not applicable.

Data Availability Statement: Not applicable.

Conflicts of Interest: The authors declare no conflict of interest.

\section{References}

1. National Bureau of Statistics of People's Republic of China. China Statistics Yearbook 2020; China Statistics Press: Beijing, China, 2020.

2. Barbucci, P. Enel strategy for zero emission power generation. In Proceedings of the Beijing Symposium on Sino-Italy Cooperation on Clean Coal Technology and CCS, Beijing, China, 15 December 2008.

3. Ghoniem, A.F. ENEL-MIT Clean Energy Program; MIT: Cambridge, MA, USA, October 2008. Available online: https:/ / energy.mit. edu/search/?q=Clean\%20Energy\%20Program (accessed on 10 October 2021).

4. Zheng, C.; Zhao, Y.; Guo, X. Research and Development of Oxy-fuel Combustion in China. In Proceedings of the CSEE, Kuala Lumpur, Malaysia, 8-9 March 2014; pp. 3856-3864.

5. Pei, X. Study on Pressurized Oxy-Coal Combustion Characteristics and System Energy Consumption Analysis. Ph.D. Thesis, Beijing Jiaotong University, Beijing, China, 2017. 
6. Shaddix, C.R.; Molina, A. Particle Imaging Of Ignition and Devolatilization Of Pulverized Coal During Oxy-Fuel Combustion Proc. Combust. Inst. 2009, 32, 2091-2098. [CrossRef]

7. Xu, M.; Yu, D.; Yao, H.; Liu, X.; Qiao, Y. Coal combustion-generated aerosols: Formation and properties. Proc. Combust. Inst. 2011, 33, 1681-1697. [CrossRef]

8. Hong, J.S.; Chaudhry, G.; Brisson, J.G.; Field, R.; Gazzino, M.; Ghoniem, A.F. Analysis of oxy-fuel combustion power cycle utilizing a pressurized coal combustor. Energy 2009, 34, 1332-1340. [CrossRef]

9. Lee, H.; Choi, S. An observation of combustion behavior of a single coal particle entrained into hot gas flow. Combust. Flame 2015, 162, 2610-2620. [CrossRef]

10. Yuan, Y.; Li, S.; Zhao, F.; Yao, Q.; Long, M.B. Characterization on hetero-homogeneous ignition of pulverized coal particle streams using $\mathrm{CH} *$ chemiluminescence and 3 color pyrometry. Fuel 2016, 184, 1000-1006. [CrossRef]

11. Xu, Y.; Li, S.; Yao, Q.; Yuan, Y. Investigation of Steam Effect on Ignition of Dispersed Coal Particles in $\mathrm{O}_{2} / \mathrm{N}_{2}$ and $\mathrm{O}_{2} / \mathrm{CO}_{2}$ Ambiences. Fuel 2018, 233, 388-395. [CrossRef]

12. Liu, Y.; Geier, M.; Molina, A.; Shaddix, C.R. Pulverized coal stream ignition delay under conventional and oxy-fuel combustion conditions. Int. J. Greenh. Gas Control 2011, 5, S36-S46. [CrossRef]

13. Molina, A.; Shaddix, C.R. Ignition and Devolatilization of Pulverized Bituminous Coal Particles during Oxygen/Carbon Dioxide Coal Combustion. Proc. Combust. Inst. 2007, 31, 1905-1912. [CrossRef]

14. Schiemann, M.; Scherer, V.; Wirtz, S. Optical Coal Particle Temperature Measurement under Oxy-Fuel Conditions: Measurement Methodology and Initial Results. Chem. Eng. Technol. 2009, 32, 2000-2004. [CrossRef]

15. Sun, C.L.; Zhang, M.Y. Ignition of Coal Particles at High Pressure in a Thermogravimetric Analyzer. Combust. Flame 1998, 115, 267-274. [CrossRef]

16. Yin, C.; Yan, J. Oxy-fuel combustion of pulverized fuels: Combustion fundamentals and modeling. Appl. Energy 2016, 162, 742-762. [CrossRef]

17. Ying, Z.; Zheng, X.; Cui, G. Pressurized oxy-fuel combustion performance of pulverized coal for $\mathrm{CO}_{2}$ capture. Appl. Therm. Eng. 2016, 99, 411-418. [CrossRef]

18. Zheng, L.; Pomalis, R.; Clements, B. Technical feasibility study of TIPS process and comparison with other $\mathrm{CO}_{2}$ capture power generation processes. In Proceedings of the 32nd International Technical Conference on Coal Utilization and Fuel Systems, Clearwater, FL, USA, 10-15 June 2007.

19. Li, L.; Duan, L.; Yang, Z.; Zhao, C. Pressurized oxy-fuel combustion characteristics of single coal particle in a visualized fluidized bed combustor. Combust. Flame 2020, 211, 218-228. [CrossRef]

20. Lewis, A.D. Gasification of Biomass, Coal, and Petroleum Coke at High Heating Rates and Elevated Pressure; Brigham Young University: Provo, UT, USA, 2014.

21. Ma, L. Combustion and Gasification of Chars in Oxygen and Carbon Dioxide at Elevated Pressure. Ph.D. Thesis, Stanford University, Stanford, CA, USA, 2006.

22. Schiemann, M.; Vorobiev, N.; Scherer, V. Stereoscopic Pyrometer for Char Combustion Characterization. Appl. Opt. 2015, 54, 1097. [CrossRef] [PubMed]

23. Köser, J.; Li, T.; Vorobiev, N.; Dreizler, A.; Schiemann, M.; Boehm, B. Multi-parameter diagnostics for high-resolution in-situ measurements of single coal particle combustion. Proc. Combust. Inst. 2019, 37, 2893-2900. [CrossRef]

24. Chen, Q.; Qin, D.; Li, J.; Liu, Z. A Particle-Tracking Image Pyrometer for Characterizing Ignition of Pulverized Coal Particles. Fuel Processing Technol. 2022, 225, 107065. [CrossRef]

25. Li, J. PIV Experimental Study and Direct Numerical Simulation of Gas-Solid Two-Phase Turbulence in a Horizontal Channel Ph.D. Thesis, Huazhong University of Science and Technology, Wuhan, China, 2010.

26. Levendis, Y.A.; Joshi, K.; Khatami, R.; Sarofim, A.F. Combustion Behavior in Air of Single Particles from Three Different Coal Ranks and from Sugarcane Bagasse. Combust. Flame 2011, 158, 452-465. [CrossRef] 